\title{
Drosophila atm/telomere fusion is required for telomeric localization of HP1 and telomere position effect
}

\author{
Sarah R. Oikemus, ${ }^{1}$ Nadine McGinnis, ${ }^{1}$ Joana Queiroz-Machado, ${ }^{2,3}$ Hanna Tukachinsky, ${ }^{1}$ \\ Saeko Takada, ${ }^{1}$ Claudio E. Sunkel, ${ }^{2,4}$ and Michael H. Brodsky ${ }^{1,5}$ \\ ${ }^{1}$ Program in Gene Function and Expression and Program in Molecular Medicine, University of Massachusetts Medical \\ School, Worcester, Massachusetts 01605, USA; ${ }^{2}$ Instituto de Biologia Molecular e Celular, Universidade do Porto, $4150-180$ \\ Porto, Portugal; ${ }^{3}$ Faculdade de Ciências da Saúde, Universidade Fernando Pessoa, 4150 Porto, Portugal; ${ }^{4}$ ICBAS, Universidade \\ do Porto, 4000 Porto, Portugal
}

Terminal deletions of Drosophila chromosomes can be stably protected from end-to-end fusion despite the absence of all telomere-associated sequences. The sequence-independent protection of these telomeres suggests that recognition of chromosome ends might contribute to the epigenetic protection of telomeres. In mammals, Ataxia Telangiectasia Mutated (ATM) is activated by DNA damage and acts through an unknown, telomerase-independent mechanism to regulate telomere length and protection. We demonstrate that the Drosophila homolog of ATM is encoded by the telomere fusion (tefu) gene. In the absence of ATM, telomere fusions occur even though telomere-specific Het-A sequences are still present. High levels of spontaneous apoptosis are observed in ATM-deficient tissues, indicating that telomere dysfunction induces apoptosis in Drosophila. Suppression of this apoptosis by p53 mutations suggests that loss of ATM activates apoptosis through a DNA damage-response mechanism. Loss of ATM reduces the levels of heterochromatin protein 1 (HP1) at telomeres and suppresses telomere position effect. We propose that recognition of chromosome ends by ATM prevents telomere fusion and apoptosis by recruiting chromatin-modifying complexes to telomeres.

[Keywords: Drosophila; telomere; protection; ATM; HP1; chromatin]

Supplemental material is available at http://www.genesdev.org.

Received March 11, 2004; revised version accepted May 27, 2004.

Telomeres are specialized DNA-protein structures required to replicate and protect the ends of eukaryotic chromosomes (Zakian 1995; Blackburn 2001). In most organisms, the reverse-transcriptase telomerase prevents the loss of terminal sequences by adding short repeat sequences during $S$ phase. Sequence-specific DNA-binding proteins that recognize telomere repeat sequences help regulate telomere length and protection (Cooper et al. 1997; Shore 1997; de Lange 2002; Karlseder 2003). DNA damage repair or signaling proteins also regulate telomere function (Chan and Blackburn 2002; Bertuch and Lundblad 2003), possibly by recognizing DNA structures at telomeres that resemble damaged chromosomes.

A family of proteins related to the Ataxia Telangiectasia Mutated (ATM) kinase plays conserved roles in DNA repair and telomere function. Mutations in human ATM cause the inherited cancer predisposition syndrome ataxia telangiectasia (Shiloh 2003). Loss of ATM

${ }^{5}$ Corresponding author.

E-MAIL michael.brodsky@umassmed.edu; FAX (508) 856-5460.

Article published online ahead of print. Article and publication date are at http://www.genesdev.org/cgi/doi/10.1101/gad.1202504. in humans or mice causes high levels of genomic instability and hypersensitivity to ionizing radiation. ATM phosphorylates multiple substrates, including the Chk2 checkpoint kinase and p53 transcription factor, which promote apoptosis, cell cycle arrest, and DNA repair following DNA damage. Two ATM-related kinases, ATR (ATM and Rad3-related) and DNA-PKcs (DNA-dependent protein kinase catalytic subunit), are also activated by DNA damage and cooperate with ATM to regulate the cellular response to DNA damage (Shiloh 2003). ATM also regulates telomere length and protection (Pandita et al. 1995; Metcalfe et al. 1996; Pandita 2002). ATM function is, at least partly, telomerase independent, as mice mutant for both telomerase and ATM have shorter telomeres and more anaphase bridges than single mutant mice; these mice also exhibit striking defects in stemcell populations and aging (Wong et al. 2003). Because of the intimate linkage between telomere length and telomere protection, it is difficult to determine whether the targets of ATM are enzymes that extend or degrade telomere DNA or proteins that directly mediate telomere protection. Identification of these targets may help de- 
fine telomerase-independent pathways that regulate telomere function.

Budding and fission yeast have homologs of ATM and ATR. Whereas loss of one ATM-like kinase can affect telomere length and repression of gene expression near telomeres (telomere position effect), loss of both ATM and ATR in yeast causes rapid shortening and fusion of yeast telomeres (Naito et al. 1998; Ritchie et al. 1999; Chan et al. 2001; Craven et al. 2002; Chan and Blackburn 2003). Assays that directly measure telomere protection demonstrate that these proteins prevent telomeres from being fused to double-strand DNA breaks or to other telomeres (DuBois et al. 2002; Chan and Blackburn 2003; Mieczkowski et al. 2003). As in mice, the yeast ATMlike kinases act, at least partly, in a telomerase-independent pathway (Ritchie et al. 1999; Nakamura et al. 2002; Chan and Blackburn 2003). Thus, in both yeast and humans, ATM can regulate telomere function independently of telomerase.

Analysis of telomere function in Drosophila has revealed that an epigenetic mechanism contributes to telomerase-independent protection of telomeres. Drosophila telomeres are composed of two non-LTR retrotransposons, Het-A and TART, as well as more proximal telomere-associated sequences (Biessmann et al. 1992; Karpen and Spradling 1992; Levis et al. 1993; Mason and Biessmann 1995; Cryderman et al. 1999; Fanti and Pimpinelli 1999). Terminally deleted chromosomes, lacking all telomere-specific sequences, can be isolated following DNA damage (Mason et al. 1984, 1997; Tower et al. 1993; Ahmad and Golic 1998). Once obtained, the ends of these chromosomes are protected from end-to-end fusion; this property is stably inherited despite the gradual loss of terminal sequences due to the incomplete replication of chromosome ends by DNA polymerase (Biessmann and Mason 1988). The heritable and sequence-independent protection of the ends of terminally deleted chromosomes indicates that this aspect of Drosophila telomere function can be regulated by an epigenetic mechanism.

The Drosophila heterochromatin protein 1 (HP1) and heterochromatin protein 1/ORC2 associated protein (HOAP) are localized to telomeres and required for telomere function. HP1 proteins play an evolutionarily conserved role in heterochromatin function (Eissenberg and Elgin 2000; Grewal and Elgin 2002; Kellum 2003). In Drosophila, HP1 is prominent at centromeric and telomeric heterochromatin, but is also observed at euchromatic sites (James et al. 1989; Fanti et al. 1998, 2003). HOAP forms a complex with HP1 and is strongly localized to telomeres (Shareef et al. 2001; Badugu et al. 2003). Loss of either HP1 or HOAP leads to striking telomere fusion phenotypes, suggesting that chromatin structure plays a central role in telomere protection (Fanti et al. 1998; Cenci et al. 2003). Chromatin-modifying proteins also regulate telomere position effect (TPE) in Drosophila. TPE at the second and third chromosomes is sensitive to the dose of Polycomb group genes, whereas TPE at the fourth chromosome or at a terminally deleted minichromosome is sensitive to the dose of HP1 (Cry- derman et al. 1999; Donaldson et al. 2002; Boivin et al. 2003). These results indicate that the regulation of chromatin structure by HP1 is required for both telomere protection and TPE.

Interestingly, terminally deleted chromosomes have normal levels of HP1-HOAP at their telomeres (Fanti et al. 1998; Cenci et al. 2003). The sequence-independent localization of these proteins to telomeres suggests that a structural feature of telomeres, perhaps chromosome ends, helps establish or reinforce the localization of these telomere-protection proteins. Gatti and colleagues have suggested that DNA damage-detection proteins may help recruit $\mathrm{HP1-HOAP}$ complexes to telomeres by recognizing chromosome ends (Cenci et al. 2003).

Drosophila encodes two damage-response proteins in the ATM kinase family, MEI-41, which is most similar to ATR, and CG6535/ATM, which is most similar to human ATM (Hari et al. 1995; Sekelsky et al. 2000; Laurencon et al. 2003; Brodsky et al. 2004). ATR/MEI-41 is required for ionizing radiation (IR)-induced cell cycle arrest, but not p53-dependent apoptosis (Hari et al. 1995; Ahmad and Golic 1999; Brodsky et al. 2000a,b, 2004; Ollmann et al. 2000). Telomere fusions have not been described in mitotic cells lacking ATR/MEI-41 or its binding partner, ATRIP/MUS304 (Gatti 1979; Hari et al. 1995; Brodsky et al. 2000b).

In this study, we characterize the role of Drosophila ATM in telomere function. Drosophila ATM is required for viability and for eye, wing, and bristle development. We find high frequencies of telomere fusions and anaphase bridges in the absence of ATM. We demonstrate that chromosomes mutant for the telomere fusion (tefu) gene (Queiroz-Machado et al. 2001) carry truncation mutations in $\mathrm{atm}$. In atm mutant animals, telomere fusions are accompanied by greatly elevated levels of spontaneous apoptosis during tissue growth. This apoptosis is suppressed by mutations in p53, suggesting that loss of telomere protection induces an ATM-independent, but p53-dependent, apoptotic signal. We demonstrate that ATM is specifically required for normal levels of HP1 and HOAP at telomeres, but not at centric heterochromatin. In addition, atm mutations suppress TPE, demonstrating that atm is required for normal telomere chromatin structure. In situ hybridization with telomere-specific sequences demonstrates that the telomere defects in atm mutant cells are not due to loss of telomere sequences. These results support a model for telomere protection in which the recognition of DNA structures at chromosome termini by the ATM kinase provides a sequence-independent mechanism to help recruit telomere protection proteins that modify chromatin structure.

\section{Results}

\section{A Drosophila ATM homolog}

The genomic structure of atm/CG6535 is shown in Figure $1 \mathrm{~A}$. On the basis of cDNA sequencing and transgene rescue, we have identified a functional atm cDNA (see Supplemental Material). Comparison of the predicted peptide sequence to mammalian checkpoint kinases in- 
Oikemus et al.

Figure 1. Molecular characterization of Drosophila ATM. (A) Diagram of Drosophila atm gene structure and mutations. (Black boxes) The exons of the atm gene; (blue boxes) the exons of the adjacent gene hsc70-4. (Black arrows) The direction of transcription; (red arrows) the position of the $a_{t m}^{\text {red31 }}$ and atm $^{\text {tefu }}$ point mutations. Genomic deletions are represented by a dashed line. The $\Delta 356$ deletion removes the entire hsc70-4 gene and $\sim 4 \mathrm{~kb}$ of the $5^{\prime}$ region of the atm gene. $D f(3 R) P G 4$ removes part of the hsc70-4 gene, all of atm, and an undetermined number of additional genes. $\Delta 16$ removes only a portion of the hsc70-4 gene. The $\mathrm{P}[\mathrm{zhsc} 70-4]$ transgene rescues hsc70-4 function, and when used in combination with the $\Delta 356$ deletion, results in a mutation in the atm gene. (B) Schematic representation of ATM protein domains. The percent sequence similarity for the $\mathrm{N}$-terminal region, FAT domain, and Kinase domain of Drosophila and human ATM proteins are shown. Numbers above the alignments indicate amino acid position. (Red arrows) The position of the $\mathrm{atm}^{\text {red31 }}$ and $\mathrm{atm}^{\text {tefu }}$ mutations in the ATM protein. (C) The tefu and red31 point mutations. The tefu mutation is a 4-bp insertion at cDNA nucleotide 3940 , changing cysteine 1307 to a stop codon. The red31 mutation is a single base-pair change at nucleotide 4320, changing Ser 1434 to a stop codon. Both the tefu and red31 mutations are predicted to form truncated proteins lacking the conserved FAT and Kinase domains. $(D-I)$ Adult morphology in wild-type $(D, F, H)$ and $\mathrm{atm}^{\Delta 356} / \mathrm{atm}^{\text {tefu }}(E, G, I)$ animals. atm ${ }^{-}$animals exhibit rough eyes $(E)$, notched wings $(G)$, and shorter or missing bristles ( $I$, arrows). (H) Wild-type adults have a characteristic pattern of bristles on the head with reproducible lengths and positions. (I) $\mathrm{atm}^{-}$ adults have many defective or missing bristles. Two affected bristles are marked with an arrow and an arrow head. Which bristles are affected varies among individuals.

dicates that it is the Drosophila homolog of ATM (see Supplemental Material). To characterize atm function, a deletion mutant $(\Delta 356)$ was used that disrupts part of atm and all of the adjacent gene hsc70-4 (Bronk et al. 2001; Fig. 1A). Animals homozygous for this deletion and carrying a transgene containing the hsc70-4 gene (Hing et al. 1999) can be used to study the function of atm alone (Fig. 1A). We will refer to this combination as $a^{\Delta} m^{\Delta 56}$. A second deletion, $\Delta 16$, includes $h s c 70-4$ but not $\mathrm{atm}$, and serves as an isogenic control (Bronk et al. 2001). As described below, we have also identified two mutations, atm tefu and $a^{\text {tm }}{ }^{\text {red31 }}$ that are predicted to truncate the ATM protein (Fig. 1A-C).

In contrast to Chk2 and p53, Drosophila ATM is required for normal development and viability. atm ${ }^{\Delta 356}$ animals die shortly before or after eclosion with a rough eye phenotype, misshapen wings, and missing or abnormal bristles. atm $^{\Delta 356}$ produces similar defects in combination with a deficiency, $D f(3 R) P G 4$, that includes atm
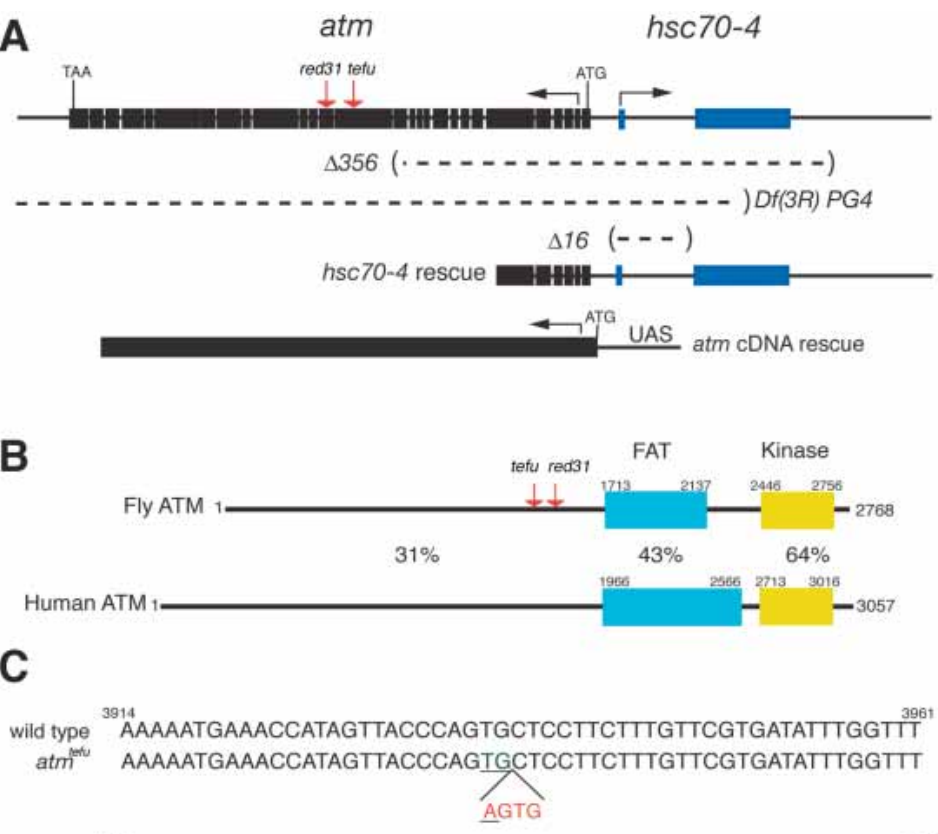

wild type ${ }^{4292}$ AGGGCGGATGTCGCCAATTATTTGCGCTCATTICTGTTAAGTCCGACGCCAGA

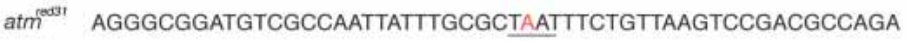
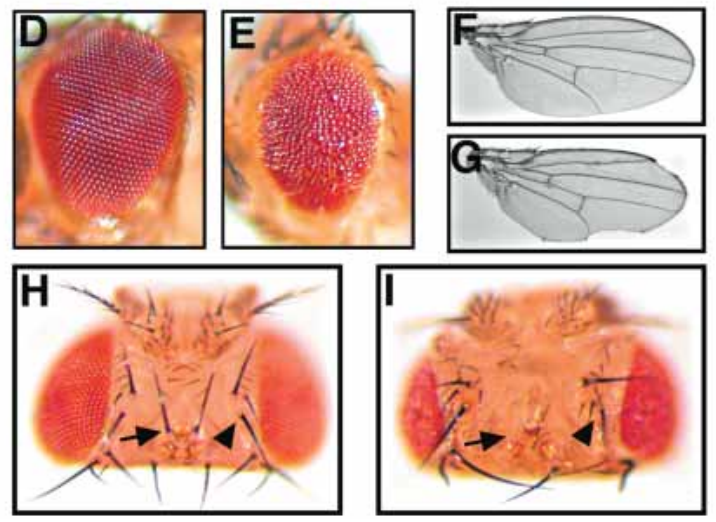

(Hing et al. 1999). atm a $^{\Delta 56} /$ atm $^{\text {tefu }}$ animals exhibit similar morphological phenotypes (Fig. 1D-I), but survive longer as adults. Defects were observed in $75 \%$ of bristles and $90 \%$ of wings (Supplementary Tables 1, 2). atm $^{\text {red31 }}$ homozygotes are also viable with rough eyes, but weaker wing and bristle phenotypes /data not shown). Similar eye and bristle phenotypes have been previously observed in Drosophila following DNA damage, or in mutant strains with high levels of genomic instability (Engels et al. 1987; Ashburner 1989; Ahmad and Golic 1999; Brodsky et al. 2000b). Extensive aneuploidy is predicted to disrupt bristle morphology, because bristles are sensitive to haploinsufficiency of ribosomal genes, which are present on all major chromosome arms (Ashburner 1989). In our experiments, the specific bristles affected varied between individuals, consistent with aneuploidy in a variable subset of cells, rather than a specific defect in the pattern of bristle cell specification. 
To confirm that these phenotypes were due to loss of ATM, the Gal4-UAS system (Brand and Perrimon 1993) was used to demonstrate that an $\mathrm{atm}$ cDNA could rescue the observed atm phenotypes (Supplemental Material). In addition, these experiments indicate that overexpression of atm does not disrupt normal development. Together, these results demonstrate that Drosophila atm has an essential role during normal development and identify a cDNA sequence sufficient to rescue ATM function.

atm mutant tissues have high levels of spontaneous apoptosis

Because human ATM is required for damage-induced apoptosis, apoptosis was examined in animals mutant for Drosophila atm. Late third-instar larvae were irradiated with 0 or 4000 rads of ionizing radiation (IR), and wing imaginal discs were stained for apoptotic cells using either the vital dye acridine orange (Fig. 2A-E) or an antibody specific for an activated form of Caspase 3 (Fig. 2F-O). In apical sections of discs stained for activated Caspase (Fig. 2F-J), apoptotic cells are dispersed among living cells. Basal sections (Fig. 2K-O) highlight apoptotic cells with pyknotic nuclei, suggesting that these basal cells had progressed to late apoptotic stages.

Untreated wild-type discs exhibit very low levels of apoptosis (Fig. 2A,F,K). IR induces a substantial increase in the number of apoptotic cells throughout the wing disc (Fig. 2B,G,L). Untreated wing discs from atm ${ }^{-}$animals exhibit extremely high levels of spontaneous apoptosis, particularly in the basal region of the disc (Fig. $2 \mathrm{C}, \mathrm{H}, \mathrm{M})$. Because of the spontaneous apoptosis in $\mathrm{atm}^{-}$ discs, it is difficult to determine whether IR can induce increased apoptosis in the disc as a whole (Fig. 2D) or in basal sections of the disc (Fig. 2N). However, most cells in the apical region of $\mathrm{atm}^{-}$wing discs are not apoptotic (Fig. 2I). In contrast to wild-type discs (Fig. 2F,G), atm discs do not show a substantial increase in apical apoptotic cells following IR (Fig. 2H,I). These results indi- cate that $\mathrm{atm}$ is required both to suppress spontaneous apoptosis during development and for normal induction of apoptosis in response to IR.

We considered the possibility that the spontaneous apoptosis in $\mathrm{atm}^{-}$discs is due to activation of a DNA damage-response pathway. Because Drosophila p53 is required for DNA damage-induced apoptosis, the effect of a null mutation in p53 (Rong et al. 2002; Brodsky et al. 2004) on the spontaneous apoptosis and lethality due to loss of atm was examined. Compared with atm singlemutant animals, atm ${ }^{\Delta 356}, p 53^{1}$ double-mutant animals exhibit substantially reduced levels of acridine orange staining (Fig. 2E), activated caspase staining (Fig. 2J,O), and pyknotic nuclei (data not shown). Although most apoptosis is suppressed by removal of p53, the levels of spontaneous apoptosis in atm, p53 mutant discs are still elevated compared with wild type (Fig. 2, cf. A,F,K and $\mathrm{E}, \mathrm{J}, \mathrm{O})$, revealing some p53-independent apoptosis. Loss of p53 did not rescue atm lethality, as double-mutant animals still died as pharate adults with missing or defective bristles (data not shown). Thus, most of the spontaneous apoptosis in $\mathrm{atm}^{-}$animals is p53 dependent, but suppression of that apoptosis is not sufficient to restore normal development or viability.

\section{atm is not required for damage-induced cell cycle arrest}

Because human cells lacking ATM are defective in cell cycle arrest following ionizing irradiation (IR), the role of Drosophila ATM in damage-induced cell cycle arrest was tested. The wing imaginal disc exhibits a G2/M DNA damage checkpoint following X-irradiation, which is dependent on Drosophila homologs of ATR and ATRIP (Hari et al. 1995; Brodsky et al. 2000b). Both wildtype and $\mathrm{atm}^{-}$wing discs exhibit a reduction in the number of mitotic cells at time points from 1 to $8 \mathrm{~h}$ following X-irradiation (Fig. 3A-C,E-G; data not shown). Thus, Drosophila ATM is not essential for G2 arrest following DNA damage.
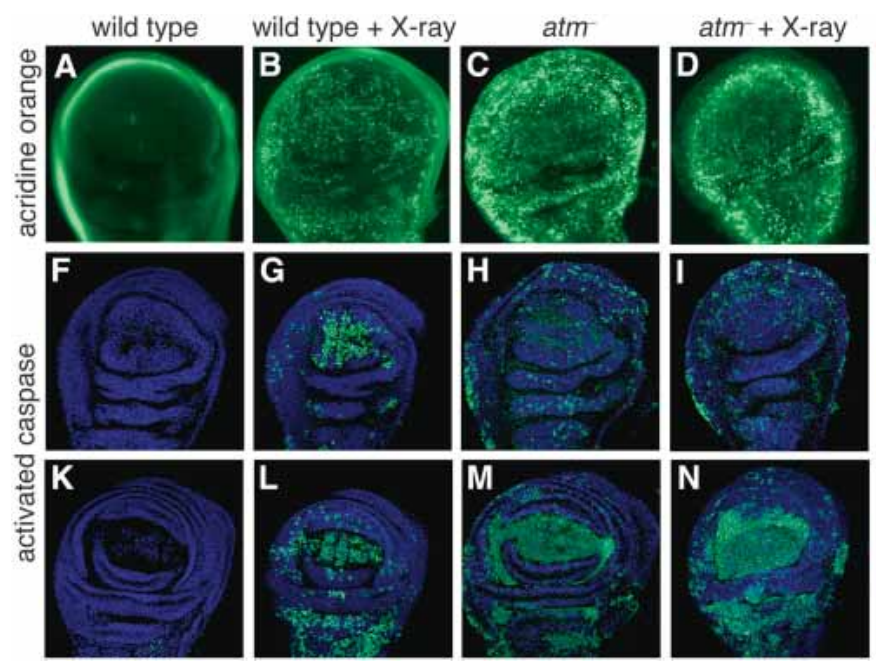

atm, $p 53$
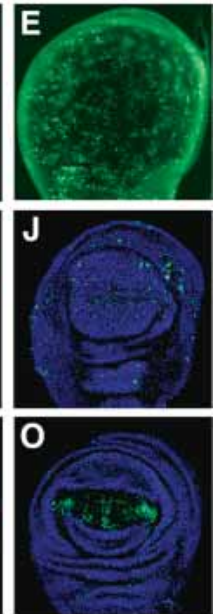

Figure 2. p53-dependent apoptosis in atm mutant wing discs. Third-instar larval wing discs were mock treated or irradiated with 4000 rads X-rays and stained with acridine orange $(A-E)$ or an antibody to activated Caspase 3 and DAPI $(F-O)$ to detect apoptotic cells. Cells in late stages of apoptosis accumulate in the basal regions of the wing disc $(K-O)$, whereas cells in earlier stages are visible in apical regions $(F-J)$. In wild-type discs, levels of apoptosis are low prior to irradiation $(A, F, K)$ and are induced following irradiation $(B, G, L)$. High levels of apoptosis are observed in untreated $(C, H, M)$ and irradiated $(D, I, N) \mathrm{atm}^{-}$ discs. (I) Apoptosis is not increased in $\mathrm{atm}^{-}$ wing discs following irradiation. $(E, J, O)$ Apoptosis is strongly suppressed in atm, p53 double-mutant discs. These experiments were repeated with 10-20 discs per panel. 
Oikemus et al.
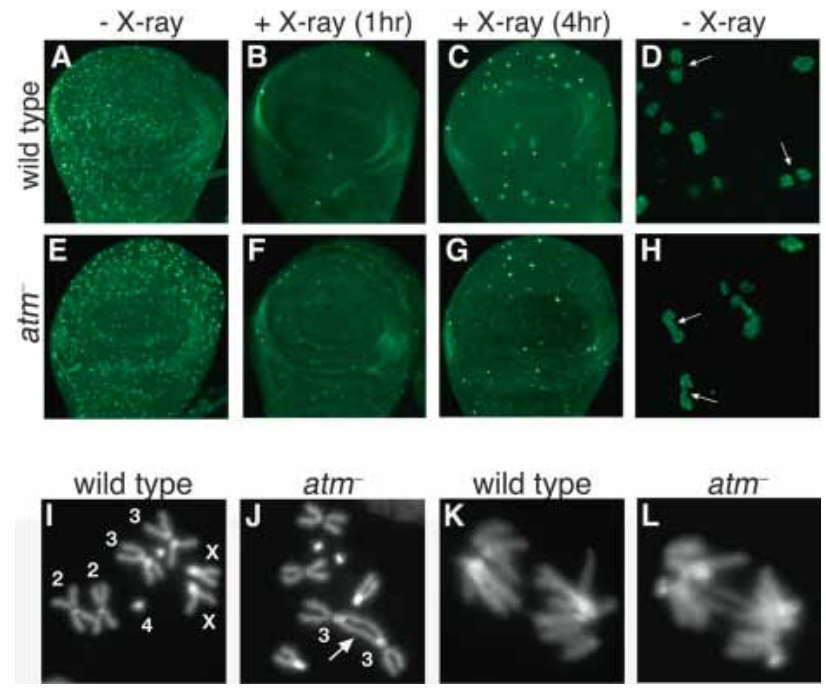

Figure 3. atm is not required for damage-induced cell cycle arrest. Third instar larval wing discs were stained with a mitosis-specific antibody against phospho-histone H3. The pattern of mitotic cells in wild-type $(A-D)$ and $a^{-}(E-H)$ discs is shown following no irradiation $(A, D, E, H)$ or $1 \mathrm{~h}(B, F)$ or $4 \mathrm{~h}$ $(C, G)$ after irradiation with 4000 rads X-rays. Mitosis is blocked in both wild-type and $\mathrm{atm}^{-}$wing discs. At higher magnification, anaphase bridges (arrows) are seen in $\mathrm{atm}^{-}(H)$ but not in wildtype $(D)$ discs. Metaphase $(I, J)$ and anaphase $(K, L)$ neuroblasts were prepared from wild-type and $a^{-}$third-instar larval brains. $(I, K)$ Wild-type metaphases and anaphases show no associations between telomeres. $(J, L) \mathrm{atm}^{-}$cells exhibit telomere fusions and anaphase bridges. More examples of telomere fusions are shown in Supplementary Figure 1. The frequencies of metaphase chromosome aberrations and anaphase bridges are shown in Supplementary Tables 3 and 4.

Interestingly, higher magnification of the mitotic cells in unirradiated $\mathrm{atm}^{-}$discs revealed anaphase bridges not observed in wild-type discs (Fig. 3D,H). Anaphase bridges are typically the result of dicentric chromosomes entering mitosis. These results suggest that $\mathrm{atm}$ is required to prevent the formation of dicentric chromosome aberrations such as fusions or translocations.

atm is required to prevent telomere fusions and is mutated in telomere fusion animals

To examine chromosome structure in $\mathrm{atm}^{-}$animals, metaphase and anaphase chromosomes were prepared from wild-type and $\mathrm{atm}^{-}$larval neuroblasts. $\mathrm{atm}^{-}$neuroblasts exhibit a high frequency of chromosome end fusions and anaphase bridges (Fig. 3I-L; Supplementary Fig. 1; Supplementary Tables 3, 4). The aberrations observed indicate that Drosophila ATM is required to protect telomeres from fusion, and that these unprotected telomeres can undergo at least one round of a fusionbridge-break cycle.

The telomere fusion phenotype observed in $\mathrm{atm}^{-}$neuroblasts resembles the mutant phenotype of the previ- ously described tefu gene (Queiroz-Machado et al. 2001). tefu maps near atm by meiotic recombination and fails to complement a chromosome with a deficiency $[D f(3 R)$ red31] in cytological region 88B5-C. Although atm is in $88 \mathrm{E} 3, a^{-1 m}{ }^{\Delta 356}$ mutations fail to complement both tefu and $D f(3 R)$ red31 for multiple phenotypes. tefu and $D f(3 R)$ red31 also fail to complement $D f(3 R) P G 4$, which encompasses the atm locus. The phenotypes of $\mathrm{atm}^{\Delta 356} /$ tefu animals can be rescued by expression of the atm cDNA. Sequencing reveals that both the tefu and $D f(3 R)$ red31 chromosomes contain stop mutations in atm (Fig. 1). To demonstrate that the phenotype associated with the $D f(3 R)$ red31 is not associated with the described deletion, the atm mutation was separated from the deletion by meiotic recombination. Thus, atm and telomere fusion are the same gene. There are some minor differences between the phenotypes previously described for homozygous tefu animals and those described in this study; these could be due to a closely linked second mutation on the tefu chromosome.

The effects of different alleles of atm on anaphase bridge frequencies were compared (Supplementary Table 4). Animals homozygous for atm $^{\Delta 356}$ or heterozygous for $a^{-m^{\Delta 56}}$ and a deficiency that encompasses atm exhibited similar frequencies of anaphase bridges, suggesting that this allele is a strong, loss-of-function allele. Animals heterozygous for an atm deficiency and either tefu or $D f(3 R)$ red31 have similar frequencies of bridges.

\section{atm mutations reduce HP1 and HOAP levels at telomeres and suppress telomere position effect}

The phenotypes described above indicate that Drosophila atm is required to protect telomeres from fusion. HP1 and HOAP localize to the telomeres of polytene chromosomes, as well as other sites, and are required for telomere protection in mitotic cells (James et al. 1989. Fanti et al. 1998; Shareef et al. 2001; Cenci et al. 2003). Immunostaining was used to examine the distribution of HP1 and HOAP on wild-type and $\mathrm{atm}^{-}$polytene chromosomes (Fig. 4). Wild-type and $\mathrm{atm}^{-}$polytene chromosomes were prepared in parallel, all samples were treated with the same antibody solutions, and all images were captured using the same exposure times. For each genotype, chromosomes were prepared from 10 different animals and immunostained with antibodies to both proteins. DNA was detected by DAPI staining. HP1 staining at the chromocenter, fourth chromosome, and several euchromatic sites is unaffected by loss of atm, whereas $\mathrm{HP} 1$ staining is reduced at most $\mathrm{atm}^{-}$telomeres (Fig. 4C,D,G,H; Supplementary Table 5). At the tip of chromosome $2 \mathrm{R}$, similar levels of HP1 staining at an internal site (cytological position 60F, arrows in Fig. 4 insets) can be observed in wild-type and mutant chromosomes, whereas HP1 is specifically reduced at the telomere of the mutant chromosome (asterisks in Fig. 4 insets). Similar HP1 staining at wild-type and mutant chromosomes was observed using a second, rabbit polyclonal HP1 antibody (data not shown). The normal levels of HP1 at 

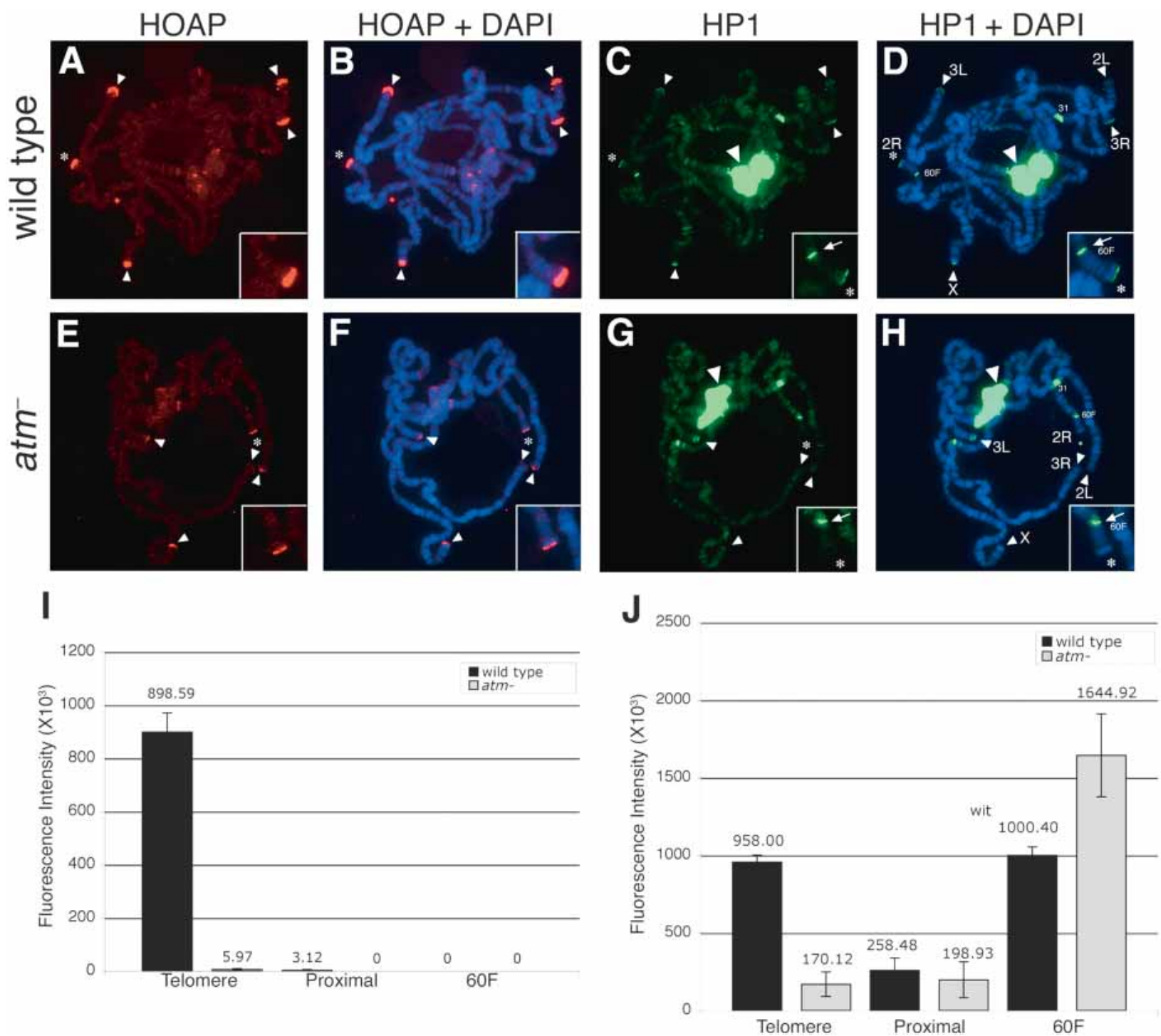

Figure 4. Reduced HP1 and HOAP levels at atm mutant telomeres. Wild-type $(A-D)$ and $a m^{-}(E-H)$ polytene chromosomes were immunostained with antibodies against $\operatorname{HOAP}(A, B, E, F)$ and $\operatorname{HP} 1(C, D, G, H) .(B, D, F, H)$ Chromosomal DNA was stained with DAPI. All telomeres are marked with arrowheads except for $2 \mathrm{R}$, which is marked with an asterisk. (Insets) Higher-magnification view of the telomere of chromosome 2R. Strong HOAP staining is observed at wild-type telomeres $(A, B)$, but is significantly reduced at atm telomeres $(E, F) .(C, D)$ Wild-type chromosomes have HP1 staining at telomeres, the chromocenter, the fourth chromosome, and at euchromatic sites. $(G, H)$ atm $^{-}$chromosomes have reduced levels of HP1 at telomeres, but normal levels at other sites. Comparison of HP1 staining at the telomere of chromosome arm 2R and a nearby euchromatic binding site (band 60F) illustrates the specific loss of telomere staining on $\mathrm{atm}^{-}$chromosomes. The total fluorescence intensity of HOAP $(I)$ and HP1 $(J)$ signal at the telomere of $2 \mathrm{R}$, a proximal region near the telomere, and band 60F was quantified for wild-type and mutant chromosomes.

sites other than the telomere indicates that the lack of telomere staining at $\mathrm{atm}^{-}$chromosomes is not due to differences in chromosome preparations or to global changes in chromatin structure in $\mathrm{atm}^{-}$cells. Rather, atm is specifically required to recruit or maintain HP1 to chromosome ends.

Immunostaining of the same chromosomes for HOAP revealed reduced staining at the telomeres of most $\mathrm{atm}^{-}$ chromosomes compared with wild type (Fig. 4A,B,E,F; Supplementary Table 5). Similar decreases in HP1 and HOAP localization at telomeres were seen in $\mathrm{atm}^{\Delta 356} /$
Df(3R)PG4 (Fig. 4) and atmefu/Df(3R)PG4 (data not shown) animals, indicating that this phenotype is not allele specific. Quantification of the fluorescence intensity associated with HOAP and HP1 staining further demonstrates that there is a reproducible reduction at $\mathrm{atm}^{-}$telomeres compared with wild type (Fig. 4I,J). In contrast, HP1 staining at an internal chromosomal site $(60 \mathrm{~F})$ is not reduced.

Because HP1 and HOAP are required to prevent telomere fusions in mitotic cells, but not salivary glands, localization of these proteins in wild-type neuroblasts 
was examined. However, the widespread distribution of HP1 on metaphase chromosomes prevents the unambiguous identification of telomeric HP1. HOAP staining was observed at the telomeres of both wild-type and mutant neuroblasts, but the staining is too variable to conclude whether it is reduced as seen in salivary glands (data not shown).

HP1 promotes heterochromatin formation, in part, by recruiting histone-modifying enzymes. To probe whether atm mutations alter chromatin at the telomeres of mitotic cells, telomere position effect (TPE) at three telomeres was examined (Fig. 5). When a white reporter gene is placed adjacent to telomere-associated sequences (TAS), gene expression is silenced (Cryderman et al. 1999; Wallrath 2000). At each site tested, TPE is partially suppressed by mutations in atm (Fig. 5A-C,E-G; Supplementary Fig. 2). In transgenes inserted at nontelomeric genomic positions, placement of the TAS from the telomere of chromosome arm $2 \mathrm{~L}$ next to the white reporter gene is sufficient to silence white expression (Kurenova et al. 1998). Unlike TAS in their normal location adjacent to telomeres, silencing by a nontelomeric TAS was not affected by atm mutations (Fig. 5D,H; Supplementary Fig. 2). These results indicate that the suppression of TPE is due to the specific action of $\mathrm{atm}$ on gene expression near telomeres.

In other organisms, loss of telomere protection can be due to the attrition or degradation of telomere repeat sequences (Blackburn 2001; Maser and DePinho 2002). In Drosophila, it is possible to recover terminal deletions that remove all telomere-specific sequences. However,

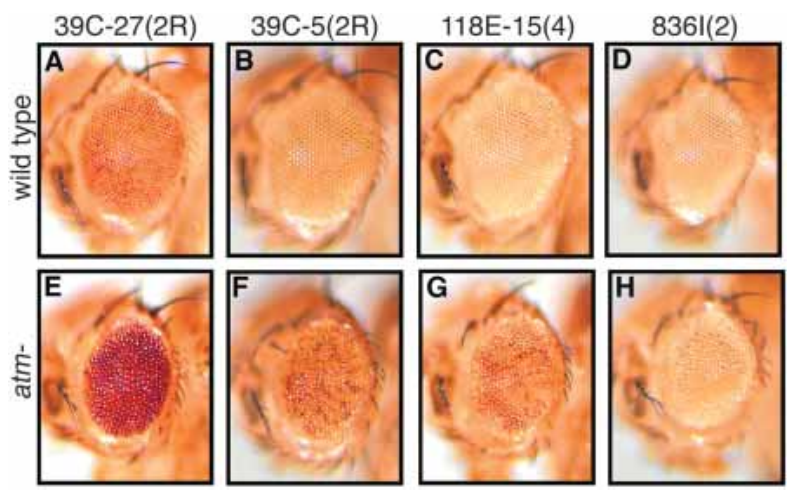

Figure 5. atm mutations suppress telomere position effect. (A$C)$ Animals hemizygous for white transgenes inserted in the telomere-associated sequence (TAS) of the right and left arms of chromosome 2 (lines 39C-27 and 39C-5) and in the telomeric region of chromosome 4 (line 118E-15) exhibit repression of the reporter gene, i.e., telomere position effect. $(D)$ A transgene containing a fusion of the white gene to $6 \mathrm{~kb}$ of TAS sequence from chromosome 2L (line 836I) also represses white expression. (E$G)$ Animals homozygous mutant for atm and hemizygous for a telomere insertion show derepression of the reporter gene. $(H)$ atm mutations do not affect repression of reporter gene expression by TAS at a nontelomeric position. Results for $\mathrm{atm}^{\text {red31/ }}$ $a^{t m}{ }^{\Delta 56}$ animals are shown and are quantified in Supplementary Figure 2. Similar results were obtained with $\mathrm{atm}^{\text {tefu }} / \mathrm{atm}^{\Delta 356}$ animals. these observations do not rule out the possibility that telomere-specific sequences contribute to telomere protection or TPE at normal Drosophila telomeres. In fact, the number of telomere repeats has been shown to influence some forms of TPE (Mason et al. 2003). To test whether the telomere defects in $\mathrm{atm}^{-}$animals could be due to loss of telomere sequences, fluorescent in situ hybridization was performed using a probe to the Het-A retrotransposon, which is specific to telomere DNA. Hybridization was performed with wild-type and $\mathrm{atm}^{-}$diploid and polytene chromosomes. In mitotic chromosomes from diploid neuroblast cells, the levels of Het-A hybridization are variable, but not significantly different between wild-type and atm mutant cells (Fig. 6A-C). In polytene chromosomes, $\mathrm{HeT}-\mathrm{A}$ sequences are strongly detected at two telomeres of both wild-type and $\mathrm{atm}^{-}$ chromosomes (Fig. 6F,G). Previous analysis of HP1 mutants demonstrated that telomere-specific sequences were still present at chromosome fusion sites (Fanti et al. 1998). In atm mutant cells, Het-A hybridization is also detected at sites of chromosome fusion (Fig. 6D,E). These results indicate that the reduction of telomeric HP1HOAP and the fusion of telomeres in $\mathrm{atm}^{-}$cells is not a direct or indirect result of telomere sequence loss.

\section{Discussion}

Both wild-type and terminally deleted Drosophila chromosomes are protected from telomere fusion and are capped with the telomere-protection proteins HP1 and HOAP (Biessmann and Mason 1988; Fanti et al. 1998; Cenci et al. 2003). These results indicate that sequenceindependent mechanisms can recruit and maintain telomere protection complexes to chromosome ends. Here, we demonstrate that Drosophila atm/tefu is required to prevent chromosome end fusions, to regulate levels of HP1 and HOAP at telomeres, and to promote telomereposition effect. We also find that atm is required for induction of apoptosis by ionizing radiation. Given the conserved role of ATM family proteins in recognizing DNA breaks, we suggest that Drosophila ATM protects telomeres by recognizing chromosome ends and recruiting chromatin-modifying proteins to those ends.

We have not, to date, directly detected ATM protein at Drosophila telomeres (S.R. Oikemus and N. McGinnis, unpubl.). However, on the basis of results in mammalian cells, it may be necessary to develop antibodies specific for activated forms of ATM to probe ATM activity at telomeres (Bakkenist and Kastan 2003). However, several observations presented here indicate that Drosophila ATM acts at telomeres to prevent chromosome fusions. First, the chromosome rearrangements observed are consistent with a defect in telomere protection rather than translocations due to defective DNA repair or replication. Most chromosome fusions occur near the ends of chromosome arms, and we demonstrate that the fused chromosomes still contain telomeric DNA sequences. Second, we do not observe a high frequency of acentric chromosome fragments during metaphase. In animals mutant for other damage-signaling genes such as the 

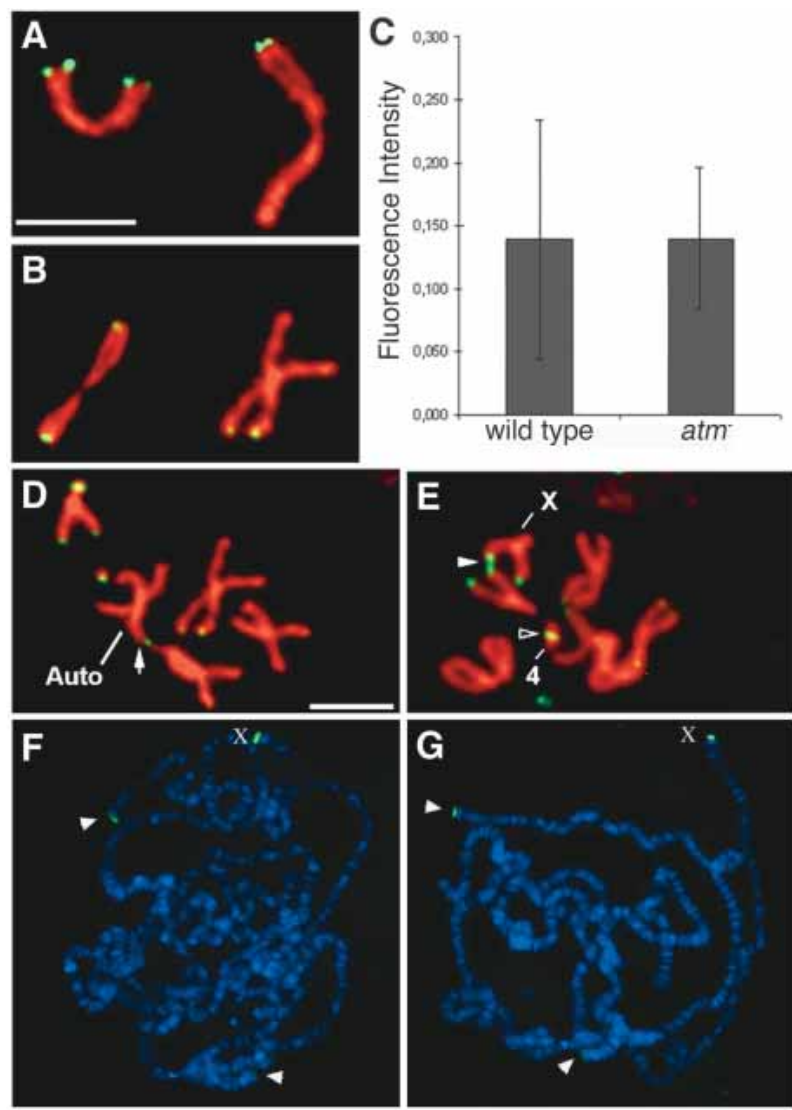

Figure 6. Analysis of Het-A sequences in atm mutant cells Wild-type and $\mathrm{atm}^{-}$chromosomes were hybridized with a DNA probe to the telomere-specific retrotransposon $H e T-A$ in mitotic and polytene cells. Mitotic chromosomes from control $(A)$ and $a_{t m}^{\text {tefu }}(B)$ neuroblast cells were hybridized with a probe for Het- $A$ (green) and the DNA was counterstained with propidium iodide (red). (C) The fluorescent intensity of the Het-A signal at the telomeres of the two large autosomes was quantified in controls $(n=31)$ and atm $^{\text {tefu }}(n=19)$ cells. The results do not show significant difference in intensity between controls and mutant cells, suggesting that the mutant has not lost telomeric sequences. $(D, E) \mathrm{atm}^{\text {tefu }}$ mutant cells showing telomere fusions that hybridize with a probe for Het-A. (D) Het-A sequences are shown at the site of telomere fusion (arrow) between two autosomes. (E) Het-A sequences extend along the entire fusion site (arrowhead) between two X chromosomes. This cell also has Het- $A$ sequences at a site at which two fourth chromosomes are joined (black arrowhead). $(F, G)$ Wild-type and $\mathrm{atm}^{-}$polytene chromosomes show similar levels of Het-A hybridization. Polytene chromosomes from control $(F)$ and atm $^{\Delta 356}(G)$ salivary gland cells were hybridized with a probe for Het-A (in green) and counterstained with DAPI (blue). Het- $A$ hybridization to autosomal telomeres is marked with arrowheads. Staining at the $\mathrm{X}$-chromosome telomeres is marked with an X.

Drosophila homologs of ATR and ATRIP, acentric chromosome fragments are often observed during metaphase, suggesting that these mutations cause a defect in DNA repair or replication that is not observed in $\mathrm{atm}^{-}$animals (Gatti 1979; Brodsky et al. 2000b). Third, circular chromosomes do not undergo rearrangements in atm ${ }^{\text {tefu }} \mathrm{mu}-$ tant animals (Queiroz-Machado et al. 2001), strongly in- dicating that chromosome fusions are due to fusion of existing chromosome ends rather than the creation of new chromosome breaks. Fourth, we show that ATM is specifically required for localization of HP1 to telomeres but not centromeric or euchromatic sites. Finally, we demonstrate that loss of atm suppresses silencing by telomere-associated sequences when they are adjacent to telomeres, but not when they are at euchromatic sites.

The telomere fusion defect seen in $\mathrm{atm}^{-}$animals is consistent with a partial defect in telomere protection. Whereas $\sim 80 \%$ of $\mathrm{atm}^{-}$metaphases contain a chromosome fusion, $>95 \%$ of metaphases from animals lacking HP1 or HOAP contain a fusion (Fanti et al. 1998; Cenci et al. 2003). Furthermore, in some cells lacking HP1 or HOAP, nearly all telomeres appear to be fused. We have not observed this extreme phenotype in atm mutant nuclei. Consistent with a partial defect in telomere protection, we find that the levels of HP1 and HOAP at polytene telomeres are reduced, but not eliminated, in $\mathrm{atm}^{-}$ animals. In mitotic cells, formation of repressive chromatin is also partially disrupted. Our interpretation of these results is that reduced and variable levels of HP1 at the telomeres of $\mathrm{atm}^{-}$animals are sufficient to protect some, but not all telomeres from fusion. Our results also indicate that another pathway, possibly involving other DNA damage-response proteins, must contribute to HP1 and HOAP localization, TPE, and telomere protection.

The direct target of ATM at telomeres is unclear. The decrease in HP1 and HOAP levels at $\mathrm{atm}^{-}$telomeres is not due to a loss of telomere sequences; wild-type and $\mathrm{atm}^{-}$chromosomes exhibit similar levels of a telomerespecific retrotransposon sequence as assayed by FISH, and even sites of fusion retain this sequence. This result is consistent with previous demonstrations that the sequences at chromosome ends are not required for telomere protection or for telomeric localization of HP1 and HOAP (Biessmann et al. 1990; Fanti et al. 1998; Cenci et al. 2003). Instead, ATM is likely to affect the interaction of HP1 and HOAP with telomeres by regulating the formation of the HP1-HOAP complex or by modification of telomeric chromatin. Other proteins in the DNA damage-response pathway may act with ATM to maintain telomere protection. Although Chk1, Chk2, and p53 are targets of mammalian ATM during the DNA damage response (Shiloh 2003), Drosophila homologs of these proteins do not appear to be required for telomere protection, as animals lacking one or more of these genes do not exhibit the high levels of apoptosis associated with loss of ATM (Brodsky et al. 2004). Mutations in homologs of other ATM targets such as NBS1 or SMC1 have not been described in Drosophila.

Recruitment of HP1 and HOAP by ATM is likely to alter chromatin structure at telomeres. HP1 plays a conserved role in heterochromatin formation, histone modification, and gene silencing (Eissenberg and Elgin 2000; Grewal and Elgin 2002). In Drosophila, both HP1 and HOAP are required for gene silencing at pericentric heterochromatin (Eissenberg et al. 1990; Eissenberg and Elgin 2000; Badugu et al. 2003). In addition, HP1 is required for gene silencing near fourth chromosome and termi- 
nally deleted telomeres, and for repression of P-element transposition by subtelomeric P-element insertions (Ronsseray et al. 1996, 1998; Cryderman et al. 1999; Donaldson et al. 2002). HP1 homologs are also associated with telomere function in other eukaryotes. In mammals, all three HP1 homologs are found at telomeres, and loss of histone $\mathrm{H} 3$ methylases leads to reduced levels of HP1 homologs at telomeres as well as elongated telomeres (Garcia-Cao et al. 2004). In contrast, overexpression of mammalian HP1 homologs is associated with decreased telomere length (Sharma et al. 2003). The fission yeast homolog of HP1 is not required for telomere protection, but does regulate telomere length, telomere clustering, and telomeric gene silencing (Allshire et al. 1995; Ekwall et al. 1995; Koering et al. 2002; Garcia-Cao et al. 2004). Interestingly, as in Drosophila telomere protection, some aspects of telomere function in fission yeast are controlled by an epigenetic mechanism (Sadaie et al. 2003). Together, these observations indicate that a requirement for HP1 in telomere function and chromatin structure is conserved, but that its precise role at the telomere may differ among organisms.

Regulation of telomere chromatin structure is also a conserved function of ATM-like kinases. Fission yeast Rad3 and budding yeast Mec1 are required for gene silencing at telomeres (Matsuura et al. 1999; Craven and Petes 2000) and mutations in human ATM are associated with altered nucleosomal periodicity at telomeres (Smilenov et al. 1999). The conserved role of ATM-kinases in telomere protection (see beginning of this paper) and telomeric chromatin structure suggests that these functions might be linked. Our finding that Drosophila ATM is required for TPE and HP1-HOAP localization to telomeres demonstrates one mechanism by which ATM can influence telomere chromatin. It is possible that in organisms that utilize sequence-specific binding proteins such as TRF2 to protect telomeres, regulation of telomeric heterochromatin by ATM and HP1 plays a minor role in protection of normal telomeres, but a more important role at short telomeres that cannot recruit sufficient levels of TRF2. Such a model might explain the synergistic telomere defects seen in cells lacking both telomerase and ATM (Ritchie et al. 1999; Tsukamoto et al. 2001; Chan and Blackburn 2003; Wong et al. 2003). The lack of an obvious TRF2 homolog may explain why ATM and HP1 play such striking roles in the protection of Drosophila telomeres.

In addition to preventing chromosome end fusion by DNA repair enzymes, telomere protection is required to prevent activation of DNA damage responses, including the induction of p53-dependent apoptosis and senescence (Chin et al. 1999; Karlseder et al. 1999; d'Adda di Fagagna et al. 2003; Takai et al. 2003). Our analysis of the cellular effects of ATM loss indicates that induction of p53-dependent apoptosis is a conserved consequence of unprotected telomeres in metazoans. Because these unprotected telomeres lead to anaphase bridges and chromosome breaks, p53 may be directly activated by unprotected telomeres or may be activated by subsequent chromosome breaks. Drosophila ATM is required for the induction of apoptosis following IR. Because the spontaneous apoptosis in $\mathrm{atm}^{-}$animals is, by definition, ATM independent, a different pathway must be able to activate Drosophila p53 in response to unprotected telomeres. Similarly, loss of mammalian ATM reduces, but does not eliminate p53-dependent apoptosis in response to unprotected telomeres (van Steensel et al. 1998; Takai et al. 2003; Wong et al. 2003). Other DNA damage-response pathways may activate Drosophila p53 in the absence of ATM.

In yeast, insects, and mammals, ATM-kinases are required to activate cellular responses to DNA ends generated by exogenous DNA damage, but also to suppress activation of these pathways by telomeres. Specific recognition of telomere sequences by telomere repeat-binding proteins provides one means to distinguish telomeric DNA ends from damage-induced DNA breaks. However, this mechanism is not sufficient to explain the epigenetic regulation of telomere protection in Drosophila. The requirement of ATM to recruit HP1 and HOAP to Drosophila telomeres suggests that recognition of chromosome ends contributes to chromatin-mediated telomere protection. This model may help explain how terminally deleted chromosomes can be stably inherited without any telomere-specific sequences. Future studies should reveal which other damage response proteins help ATM protect telomeres, what their targets are at telomeres, and how these proteins distinguish between damage-induced DNA ends and the natural ends of chromosomes.

\section{Materials and methods}

Drosophila strains and sequence analysis

All animals were raised at $25^{\circ} \mathrm{C}$. The deletion mutants, atm ${ }^{\Delta 356}$ and $h s c 70-4^{\Delta 16}$ have been previously described (Bronk et al. 2001). Df(3R)PG4 and the transgenic rescue $P\left[h s c 70-4^{+}\right]$strains were described by Hing et al. (1999). The tefu mutant was described previously (Queiroz-Machado et al. 2001). A strain carrying the $D f(3 R)$ red31 chromosome was obtained from the Bloomington Stock Center. The $\mathrm{P}\left[h s c 70-4^{+}\right] ; a t m^{\Delta 356}$ strain was created by Saeko Takada. The $\mathrm{P}\left[h s c 70-4^{+}\right]$; atm $^{\Delta 356}, p 53^{1}$ strain was generated by recombination of the $\mathrm{atm}^{\Delta 356}$ and $p 53^{1}$ mutations (Rong et al. 2002). Sequence analysis was performed using genomic DNA obtained from tefu/Df(3R)PG4, Df(3R)red31/ $D f(3 R) P G 4$, and $w^{1118}$ animals. atm genomic DNA was amplified by PCR and directly sequenced using gene-specific primers.

\section{Apoptosis and checkpoint assays}

Apoptosis and cell cycle arrest was induced in developing wing discs by irradiation of late third-instar larvae with 4000 rads X-rays in a Faxitron RX650 irradiator. Apoptotic cells were detected $4 \mathrm{~h}$ following irradiation by staining with the vital dye acridine orange (Abrams et al. 1993; Hay et al. 1994) or by fixation and staining with DAPI and a polyclonal rabbit antibody raised against cleaved human Caspase 3 (Cell Signaling Technology; 1:100 dilution) and counterstained with DAPI. Mitotic cells were visualized 1-4 h after irradiation using an anti-phospho-histone H3 antibody (Upstate Biotechnology; 1:500 dilution). Secondary antibodies were used at a 1:200 dilution. Fixa- 
tion and staining was performed as described previously (Brodsky et al. 2000b).

\section{Neuroblast preparations}

Mitotic chromosome preparations were obtained from thirdinstar larval brains according to Queiroz-Machado et al. (2001). Briefly, for metaphase spreads, brains were dissected in PBS, incubated in $0.05 \mathrm{mM}$ colchicine for $30 \mathrm{~min}$, then transferred to a hypotonic solution ( $0.5 \%$ sodium citrate) for $10 \mathrm{~min}$. Brains were fixed in $45 \%$ acetic acid for $1 \mathrm{~min}$ and squashed in $60 \%$ acetic acid. The squashed brains were stained with $0.2 \mu \mathrm{g} / \mathrm{mL}$ DAPI and mounted in Vectashield. Anaphase spreads were obtained similarly except that colchicine treatment was omitted and brains were incubated in hypotonic solution for $2 \mathrm{~min}$.

\section{Immunostaining of polytene chromosomes}

Polytene chromosomes were prepared for immunostaining as described by Shareef et al. (2001). Chromosomes were incubated with rabbit polyclonal anti-HOAP (gift from R. Kellum, University of Kentucky, Lexington, KY; 1:500 dilution), mouse monoclonal C1A9 anti-HP1 (Developmental Studies Hybridoma Bank; 1:50), or rabbit polyclonal anti-HP1 (a gift from R. Kellum; $1: 1000$ ) antibodies at $4{ }^{\circ} \mathrm{C}$ overnight, followed by a 2 -h incubation at room temperature with DAPI, Cy3-conjugated sheep anti-rabbit and FITC-conjugated sheep anti-mouse (Jackson Immunoresearch Laboratories Inc; 1:200) secondary antibodies. For each genotype, salivary glands from 10 larvae were prepared and $\sim 10$ chromosomes with good morphology and distinct telomeres were analyzed from each preparation. Stained chromosomes were analyzed using a Zeiss Axioskop 2 Plus microscope equipped with an ORCA-ER digital camera (Hamamatsu) and Openlab software (Improvision). Camera exposure times were held constant within an experiment.

Fluorescence intensity was quantified by performing a $z$ series scan on the tip of chromosome 2R using a Leica TCS SP2 confocal microscope. Leica software was used to calculate the total fluorescence intensity for three regions of interest, the telomere, cytological band 60F, and a proximal chromosome region approximately midway between the telomere and 60F (background). Five $2 \mathrm{R}$ telomeres were analyzed for each genotype.

\section{In situ hybridization to polytene chromosomes}

The DIG Labeling DNA Kit (Roche) was used to make a probe from $1 \mu \mathrm{g}$ of purified PCR product using a Het-A clone (Danilevskaya et al. 1994). A total of $1 \mu \mathrm{L}$ of probe in $20 \mu \mathrm{L}$ of hybridization solution was used per slide. Salivary gland polytene chromosome squashes were prepared for hybridization by standard methods (Pardue 1994), except that the RNase treatment was not included. Slides were prehybridized at $58^{\circ} \mathrm{C}$ in a moist chamber for $1 \mathrm{~h}$ in hybridization solution $(0.6 \mathrm{mg} / \mathrm{mL}$ Fish Sperm DNA, $7.5 \mathrm{mM} \mathrm{MgCl}$, 3\% 50× Denhardt's solution, 75 $\mathrm{mM} \mathrm{NaPO}_{4}$ at $\mathrm{pH} 7.0,1 \mathrm{M} \mathrm{NaCl}$ ). Chromosome squashes were hybridized with the DIG-labeled probe overnight at $58^{\circ} \mathrm{C}$. Hybridized probe and DNA were detected with sheep anti-DIG FITC (Roche; 1:200 dilution) and $0.5 \mu \mathrm{g} / \mathrm{mL}$ DAPI. Images were acquired as described for HP1 and HOAP staining above.

\section{In situ hybridization to mitotic chromosomes}

In situ hybridization to mitotic chromosomes was performed as described (Carmena et al. 1993). Het-A probe was labeled with biotin-14-dUTP using the Bionick Translation System (GIBCOBRL). Slides were mounted in Vectashield containing $5 \mathrm{mg} / \mathrm{mL}$ of propidium iodide as a DNA counterstain. Quantification of the Het-A fluorescence intensity was performed using the Image J software package. For each Het-A signal selected, average pixel intensity was determined and multiplied by the corresponding area.

\section{Acknowledgments}

We especially thank Rebecca Kellum for antibodies to HOAP and HP1. We thank Mary-Lou Pardue for the HeT-A probe and Lori Wallrath, James Mason, Spyros Artavanis-Tsakonas, Peter Bronk, Konrad Zinsmaier, and the Bloomington Stock Center for providing Drosophila stocks. We thank Nathan Lawson for use of his dissection microscope and camera. We thank Nick Rhind and Neal Silverman for comments on the manuscript. Work in the laboratory of C.E.S. is supported by the Fundação para a Ciência e a Technologia of Portugal, Programa POCTI. Work in the laboratory of M.H.B. was supported by an Annual Research Fund Innovation Grant from the Worcester Foundation for Biomedical Research and by a Basil O'Connor Starter Research Award from the March of Dimes Birth Defects Foundation.

The publication costs of this article were defrayed in part by payment of page charges. This article must therefore be hereby marked "advertisement" in accordance with 18 USC section 1734 solely to indicate this fact.

\section{References}

Abrams, J.M., White, K., Fessler, L.I., and Steller, H. 1993. Programmed cell death during Drosophila embryogenesis. Development 117: 29-43.

Ahmad, K. and Golic, K.G. 1998. The transmission of fragmented chromosomes in Drosophila melanogaster. Genetics 148: 775-792.

- 1999. Telomere loss in somatic cells of Drosophila causes cell cycle arrest and apoptosis. Genetics 151: 10411051.

Allshire, R.C., Nimmo, E.R., Ekwall, K., Javerzat, J.P., and Cranston, G. 1995. Mutations derepressing silent centromeric domains in fission yeast disrupt chromosome segregation. Genes \& Dev. 9: 218-233.

Ashburner, M. 1989. Drosophila: A laboratory handbook. Cold Spring Harbor Laboratory, Cold Spring Harbor, NY.

Badugu, R., Shareef, M.M., and Kellum, R. 2003. Novel Drosophila HOAP repeat motif in HP1/HOAP interactions and chromocenter associations. I. Biol. Chem. 278: 3449134498.

Bakkenist, C.J. and Kastan, M.B. 2003. DNA damage activates ATM through intermolecular autophosphorylation and dimer dissociation. Nature 421: 499-506.

Bertuch, A.A. and Lundblad, V. 2003. Which end: Dissecting $\mathrm{Ku}$ 's function at telomeres and double-strand breaks. Genes \& Dev. 17: 2347-2350.

Biessmann, H. and Mason, J.M. 1988. Progressive loss of DNA sequences from terminal chromosome deficiencies in Drosophila melanogaster. EMBO I. 7: 1081-1086.

Biessmann, H., Carter, S.B., and Mason, J.M. 1990. Chromosome ends in Drosophila without telomeric DNA sequences. Proc. Natl. Acad. Sci. 87: 1758-1761.

Biessmann, H., Champion, L.E., O'Hair, M., Ikenaga, K., Kasravi, B., and Mason, J.M. 1992. Frequent transpositions of Drosophila melanogaster HeT-A transposable elements to receding chromosome ends. EMBO T. 11: 4459-4469.

Blackburn, E.H. 2001. Switching and signaling at the telomere. 
Cell 106: 661-673.

Boivin, A., Gally, C., Netter, S., Anxolabehere, D., and Ronsseray, S. 2003. Telomeric associated sequences of Drosophila recruit polycomb-group proteins in vivo and can induce pairing-sensitive repression. Genetics 164: 195-208.

Brand, A.H. and Perrimon, N. 1993. Targeted gene expression as a means of altering cell fates and generating dominant phenotypes. Development 118: 401-415.

Brodsky, M.H., Nordstrom, W., Tsang, G., Kwan, E., Rubin, G.M., and Abrams, J.M. 2000a. Drosophila p53 binds a damage response element at the reaper locus. Cell 101: 103-113.

Brodsky, M.H., Sekelsky, J.J., Tsang, G., Hawley, R.S., and Rubin, G.M. 2000b. mus304 encodes a novel DNA damage checkpoint protein required during Drosophila development. Genes \& Dev. 14: 666-678.

Brodsky, M.H., Weinert, B.T., Tsang, G., Rong, Y.S., McGinnis, N.M., Golic, K.G., Rio, D.C., and Rubin, G.M. 2004. Drosophila melanogaster $\mathrm{MNK} / \mathrm{Chk} 2$ and $\mathrm{p} 53$ regulate multiple DNA repair and apoptotic pathways following DNA damage. Mol. Cell. Biol. 24: 1219-1231.

Bronk, P., Wenniger, J.J., Dawson-Scully, K., Guo, X., Hong, S., Atwood, H.L., and Zinsmaier, K.E. 2001. Drosophila Hsc70-4 is critical for neurotransmitter exocytosis in vivo. Neuron 30: 475-488.

Carmena, M., Abad, J.P., Villasante, A., and Gonzalez, C. 1993. The Drosophila melanogaster dodecasatellite sequence is closely linked to the centromere and can form connections between sister chromatids during mitosis. J. Cell. Sci. 105: 41-50.

Cenci, G., Siriaco, G., Raffa, G.D., Kellum, R., and Gatti, M. 2003. The Drosophila HOAP protein is required for telomere capping. Nat. Cell Biol. 5: 82-84.

Chan, S.W. and Blackburn, E.H. 2002. New ways not to make ends meet: Telomerase, DNA damage proteins and heterochromatin. Oncogene 21: 553-563.

- 2003. Telomerase and ATM/Tellp protect telomeres from nonhomologous end joining. Mol. Cell 11: 1379-1387.

Chan, S.W., Chang, J., Prescott, J., and Blackburn, E.H. 2001. Altering telomere structure allows telomerase to act in yeast lacking ATM kinases. Curr. Biol. 11: 1240-1250.

Chin, L., Artandi, S.E., Shen, Q., Tam, A., Lee, S.L., Gottlieb, G.J., Greider, C.W., and DePinho, R.A. 1999. p53 deficiency rescues the adverse effects of telomere loss and cooperates with telomere dysfunction to accelerate carcinogenesis. Cell 97: 527-538.

Cooper, J.P., Nimmo, E.R., Allshire, R.C., and Cech, T.R. 1997. Regulation of telomere length and function by a Myb-domain protein in fission yeast. Nature 385: 744-747.

Craven, R.J. and Petes, T.D. 2000. Involvement of the checkpoint protein Meclp in silencing of gene expression at telomeres in Saccharomyces cerevisiae. Mol. Cell. Biol. 20: 2378-2384.

Craven, R.J., Greenwell, P.W., Dominska, M., and Petes, T.D. 2002. Regulation of genome stability by TEL1 and MEC1, yeast homologs of the mammalian ATM and ATR genes. Genetics 161: 493-507.

Cryderman, D.E., Morris, E.J., Biessmann, H., Elgin, S.C., and Wallrath, L.L. 1999. Silencing at Drosophila telomeres: Nuclear organization and chromatin structure play critical roles. EMBO J. 18: 3724-3735.

d'Adda di Fagagna, F., Reaper, P.M., Clay-Farrace, L., Fiegler, H., Carr, P., Von Zglinicki, T., Saretzki, G., Carter, N.P., and Jackson, S.P. 2003. A DNA damage checkpoint response in telomere-initiated senescence. Nature 426: 194-198.

Danilevskaya, O., Slot, F., Pavlova, M., and Pardue, M.L. 1994. Structure of the Drosophila HeT-A transposon: A retrotrans- poson-like element forming telomeres. Chromosoma 103: 215-224.

de Lange, T. 2002. Protection of mammalian telomeres. Oncogene 21: 532-540.

Donaldson, K.M., Lui, A., and Karpen, G.H. 2002. Modifiers of terminal deficiency-associated position effect variegation in Drosophila. Genetics 160: 995-1009.

DuBois, M.L., Haimberger, Z.W., McIntosh, M.W., and Gottschling, D.E. 2002. A quantitative assay for telomere protection in Saccharomyces cerevisiae. Genetics 161: 995 1013.

Eissenberg, J.C. and Elgin, S.C. 2000. The HP1 protein family: Getting a grip on chromatin. Curr. Opin. Genet. Dev. 10: 204-210.

Eissenberg, J.C., James, T.C., Foster-Hartnett, D.M., Hartnett, T., Ngan, V., and Elgin, S.C. 1990. Mutation in a heterochromatin-specific chromosomal protein is associated with suppression of position-effect variegation in Drosophila melanogaster. Proc. Natl. Acad. Sci. 87: 9923-9927.

Ekwall, K., Javerzat, J.P., Lorentz, A., Schmidt, H., Cranston, G., and Allshire, R. 1995. The chromodomain protein Swi6: A key component at fission yeast centromeres. Science 269: 1429-1431.

Engels, W.R., Benz, W.K., Preston, C.R., Graham, P.L., Phillis, R.W., and Robertson, H.M. 1987. Somatic effects of P element activity in Drosophila melanogaster: Pupal lethality. Genetics 117: 745-757.

Fanti, L. and Pimpinelli, S. 1999. The peculiar organization of telomeres in Drosophila melanogaster. Gene Ther. Mol. Biol. 4: 1-10.

Fanti, L., Giovinazzo, G., Berloco, M., and Pimpinelli, S. 1998. The heterochromatin protein 1 prevents telomere fusions in Drosophila. Mol. Cell 2: 527-538.

Fanti, L., Berloco, M., Piacentini, L., and Pimpinelli, S. 2003. Chromosomal distribution of heterochromatin protein 1 (HP1) in Drosophila: A cytological map of euchromatic HP1 binding sites. Genetica 117: 135-147.

Garcia-Cao, M., O'Sullivan, R., Peters, A.H., Jenuwein, T., and Blasco, M.A. 2004. Epigenetic regulation of telomere length in mammalian cells by the Suv39h1 and Suv39h2 histone methyltransferases. Nat. Genet. 36: 94-99.

Gatti, M. 1979. Genetic control of chromosome breakage and rejoining in Drosophila melanogaster: Spontaneous chromosome aberrations in X-linked mutants defective in DNA metabolism. Proc. Natl. Acad. Sci. 76: 1377-1381.

Grewal, S.I. and Elgin, S.C. 2002. Heterochromatin: New possibilities for the inheritance of structure. Curr. Opin. Genet. Dev. 12: 178-187.

Hari, K.L., Santerre, A., Sekelsky, J.J., McKim, K.S., Boyd, J.B., and Hawley, R.S. 1995. The mei-41 gene of D. melanogaster is a structural and functional homolog of the human ataxia telangiectasia gene. Cell 82: 815-821.

Hay, B.A., Wolff, T., and Rubin, G.M. 1994. Expression of baculovirus P35 prevents cell death in Drosophila. Development 120: 2121-2129.

Hing, H.K., Bangalore, L., Sun, X., and Artavanis-Tsakonas, S. 1999. Mutations in the heatshock cognate 70 protein (hsc4) modulate Notch signaling. Eur. J. Cell. Biol. 78: 690-697.

James, T.C., Eissenberg, J.C., Craig, C., Dietrich, V., Hobson, A., and Elgin, S.C. 1989. Distribution patterns of HP1, a heterochromatin-associated nonhistone chromosomal protein of Drosophila. Eur. J. Cell. Biol. 50: 170-180.

Karlseder, J. 2003. Telomere repeat binding factors: Keeping the ends in check. Cancer Lett. 194: 189-197.

Karlseder, J., Broccoli, D., Dai, Y., Hardy, S., and de Lange, T. 1999. p53- and ATM-dependent apoptosis induced by telo- 
meres lacking TRF2. Science 283: 1321-1325.

Karpen, G.H. and Spradling, A.C. 1992. Analysis of subtelomeric heterochromatin in the Drosophila minichromosome Dp1 187 by single P element insertional mutagenesis. Genetics 132: 737-753.

Kellum, R. 2003. HP1 complexes and heterochromatin assembly. Curr. Top. Microbiol. Immunol. 274: 53-77.

Koering, C.E., Pollice, A., Zibella, M.P., Bauwens, S., Puisieux, A., Brunori, M., Brun, C., Martins, L., Sabatier, L., Pulitzer, J.F., et al. 2002. Human telomeric position effect is determined by chromosomal context and telomeric chromatin integrity. EMBO Rep. 3: 1055-1061.

Kurenova, E., Champion, L., Biessmann, H., and Mason, J.M. 1998. Directional gene silencing induced by a complex subtelomeric satellite from Drosophila. Chromosoma 107: 311-320.

Laurencon, A., Purdy, A., Sekelsky, J., Hawley, R.S., and Su, T.T. 2003. Phenotypic analysis of separation-of-function alleles of MEI-41, Drosophila ATM/ATR. Genetics 164: 589-601.

Levis, R.W., Ganesan, R., Houtchens, K., Tolar, L.A., and Sheen, F.M. 1993. Transposons in place of telomeric repeats at a Drosophila telomere. Cell 75: 1083-1093.

Maser, R.S. and DePinho, R.A. 2002. Connecting chromosomes, crisis, and cancer. Science 297: 565-569.

Mason, J.M. and Biessmann, H. 1995. The unusual telomeres of Drosophila. Trends Genet. 11: 58-62.

Mason, J.M., Strobel, E., and Green, M.M. 1984. mu-2: Mutator gene in Drosophila that potentiates the induction of terminal deficiencies. Proc. Nat1. Acad. Sci. 81: 6090-6094.

Mason, J.M., Champion, L.E., and Hook, G. 1997. Germ-line effects of a mutator, mu2, in Drosophila melanogaster. Genetics 146: 1381-1397.

Mason, J.M., Konev, A.Y., and Biessmann, H. 2003. Telomeric position effect in drosophila melanogaster reflects a telomere length control mechanism. Genetica 117: 319-325.

Matsuura, A., Naito, T., and Ishikawa, F. 1999. Genetic control of telomere integrity in Schizosaccharomyces pombe: $\operatorname{rad} 3(+)$ and tel1 $(+)$ are parts of two regulatory networks independent of the downstream protein kinases chk $1(+)$ and cds1(+). Genetics 152: 1501-1512.

Metcalfe, J.A., Parkhill, J., Campbell, L., Stacey, M., Biggs, P., Byrd, P.J., and Taylor, A.M. 1996. Accelerated telomere shortening in ataxia telangiectasia. Nat. Genet. 13: 350-353.

Mieczkowski, P.A., Mieczkowska, J.O., Dominska, M., and Petes, T.D. 2003. Genetic regulation of telomere-telomere fusions in the yeast Saccharomyces cerevisae. Proc. Natl. Acad. Sci. 100: 10854-10859.

Naito, T., Matsuura, A., and Ishikawa, F. 1998. Circular chromosome formation in a fission yeast mutant defective in two ATM homologues. Nat. Genet. 20: 203-206.

Nakamura, T.M., Moser, B.A., and Russell, P. 2002. Telomere binding of checkpoint sensor and DNA repair proteins contributes to maintenance of functional fission yeast telomeres. Genetics 161: 1437-1452.

Ollmann, M., Young, L.M., Di Como, C.J., Karim, F., Belvin, M., Robertson, S., Whittaker, K., Demsky, M., Fisher, W.W., Buchman, A., et al. 2000. Drosophila p53 is a structural and functional homolog of the tumor suppressor p53. Cell 101: 91-101.

Pandita, T.K. 2002. ATM function and telomere stability. Oncogene 21: 611-618.

Pandita, T.K., Pathak, S., and Geard, C.R. 1995. Chromosome end associations, telomeres and telomerase activity in ataxia telangiectasia cells. Cytogenet. Cell. Genet. 71: 86-93.

Pardue, M.L. 1994. Looking at polytene chromosomes. Methods Cell Biol. 44: 333-351.
Queiroz-Machado, J., Perdigao, J., Simoes-Carvalho, P., Herrmann, S., and Sunkel, C.E. 2001. tef: A mutation that causes telomere fusion and severe genome rearrangements in Drosophila melanogaster. Chromosoma 110: 10-23.

Ritchie, K.B., Mallory, J.C., and Petes, T.D. 1999. Interactions of TLC1 (which encodes the RNA subunit of telomerase), TEL1, and MEC1 in regulating telomere length in the yeast Saccharomyces cerevisiae. Mol. Cell. Biol. 19: 6065-6075.

Rong, Y.S., Titen, S.W., Xie, H.B., Golic, M.M., Bastiani, M., Bandyopadhyay, P., Olivera, B.M., Brodsky, M., Rubin, G.M., and Golic, K.G. 2002. Targeted mutagenesis by homologous re combination in D. melanogaster. Genes \& Dev. 16: 1568-1581.

Ronsseray, S., Lehmann, M., Nouaud, D., and Anxolabehere, D. 1996. The regulatory properties of autonomous subtelomeric $\mathrm{P}$ elements are sensitive to a Suppressor of variegation in Drosophila melanogaster. Genetics 143: 1663-1674.

Ronsseray, S., Marin, L., Lehmann, M., and Anxolabehere, D. 1998. Repression of hybrid dysgenesis in Drosophila melanogaster by combinations of telomeric P-element reporters and naturally occurring P elements. Genetics 149: 1857-1866.

Sadaie, M., Naito, T., and Ishikawa, F. 2003. Stable inheritance of telomere chromatin structure and function in the absence of telomeric repeats. Genes \& Dev. 17: 2271-2282.

Sekelsky, J.J., Brodsky, M.H., and Burtis, K.C. 2000. DNA repair in Drosophila: Insights from the Drosophila genome sequence. J. Cell Biol. 150: F31-F36.

Shareef, M.M., King, C., Damaj, M., Badagu, R., Huang, D.W., and Kellum, R. 2001. Drosophila heterochromatin protein 1 (HP1)/origin recognition complex (ORC) protein is associated with HP1 and ORC and functions in heterochromatininduced silencing. Mol. Biol. Cell 12: 1671-1685.

Sharma, G.G., Hwang, K.K., Pandita, R.K., Gupta, A., Dhar, S., Parenteau, J., Agarwal, M., Worman, H.J., Wellinger, R.J., and Pandita, T.K. 2003. Human heterochromatin protein 1 isoforms $\mathrm{HP} 1(\mathrm{Hs} \alpha)$ and $\mathrm{HP} 1(\mathrm{Hs} \beta)$ interfere with hTERT-telomere interactions and correlate with changes in cell growth and response to ionizing radiation. Mol. Cell. Biol. 23: 8363-8376.

Shiloh, Y. 2003. ATM and related protein kinases: Safeguarding genome integrity. Nat. Rev. Cancer 3: 155-168.

Shore, D. 1997. Telomere length regulation: Getting the measure of chromosome ends. Biol. Chem. 378: 591-597.

Smilenov, L.B., Dhar, S., and Pandita, T.K. 1999. Altered telomere nuclear matrix interactions and nucleosomal periodicity in ataxia telangiectasia cells before and after ionizing radiation treatment. Mol. Cell. Biol. 19: 6963-6971.

Takai, H., Smogorzewska, A., and de Lange, T. 2003. DNA damage foci at dysfunctional telomeres. Curr. Biol. 13: 1549-1556.

Tower, J., Karpen, G.H., Craig, N., and Spradling, A.C. 1993. Preferential transposition of Drosophila P elements to nearby chromosomal sites. Genetics 133: 347-359.

Tsukamoto, Y., Taggart, A.K., and Zakian, V.A. 2001. The role of the Mre11-Rad50-Xrs2 complex in telomerase-mediated lengthening of Saccharomyces cerevisiae telomeres. Curr. Biol. 11: 1328-1335.

van Steensel, B., Smogorzewska, A., and de Lange, T. 1998. TRF2 protects human telomeres from end-to-end fusions. Cell 92: 401-413.

Wallrath, L.L. 2000. Drosophila telomeric transgenes provide insights on mechanisms of gene silencing. Genetica 109: 25-33.

Wong, K.K., Maser, R.S., Bachoo, R.M., Menon, J., Carrasco, D.R., Gu, Y., Alt, F.W., and DePinho, R.A. 2003. Telomere dysfunction and Atm deficiency compromises organ homeostasis and accelerates ageing. Nature 421: 643-648.

Zakian, V.A. 1995. Telomeres: Beginning to understand the end. Science 270: 1601-1607. 


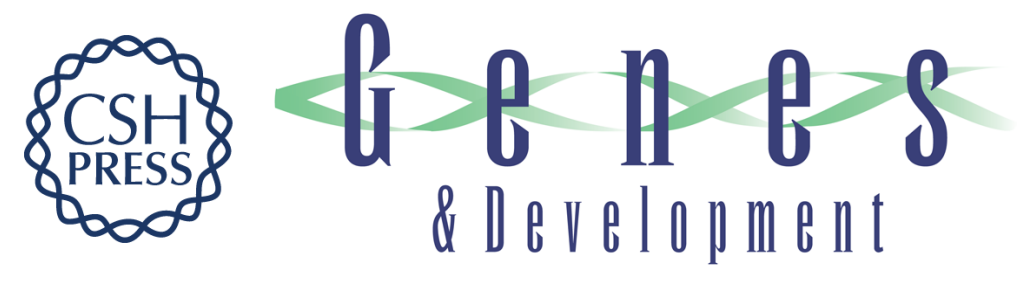

\section{Drosophila atm/telomere fusion is required for telomeric localization of HP1 and telomere position effect}

Sarah R. Oikemus, Nadine McGinnis, Joana Queiroz-Machado, et al.

Genes Dev. 2004, 18:

Access the most recent version at doi:10.1101/gad.1202504

Supplemental
Material http://genesdev.cshlp.org/content/suppl/2004/07/16/1202504.DC1

References This article cites 85 articles, 41 of which can be accessed free at:

http://genesdev.cshlp.org/content/18/15/1850.full.html\#ref-list-1

License

Email Alerting

Receive free email alerts when new articles cite this article - sign up in the box at the top

Service

right corner of the article or click here.

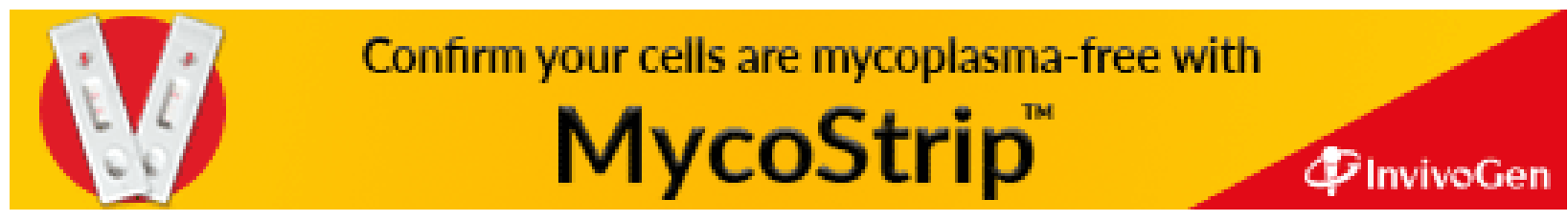

